\section{Three journals raise doubts on validity of Canadian studies}

\author{
Caroline White London
}

Suspicions about the validity of research by Professor Ranjit Kumar Chandra, a prominent Canadian researcher, have been raised by three journals, including the $B M J$.

The latest concern, in an editorial and a letter in the November issue of Nutrition (2003;19:955-6 and 976-80), question research published in that journal by Professor Chandra in September 2001 (17:70912).

The Nutrition study was a randomised, blind, placebo controlled trial. It showed that a specific multivitamin and mineral supplement could improve cognitive function in people aged over 65 years. Professor Chandra, who was the sole author, concluded that the supplement might delay the onset of Alzheimer's disease.

The original paper and the most recent letter and editorial questioning its validity have attracted considerable media attention.

\section{The BMJ's statistical reviewer concluded that the data had "all the hallmarks of being entirely invented."}

The 2001 paper in Nutrition is almost identical to a paper submitted to the $B M J$ in October 2000, which followed up a trial published in the Lancet in 1992 (340:1124-7).

The $B M J$ paper was not published because of serious problems identified during peer review. These problems included the lengthy period between the Lancet trial and submission of the manuscript on the same set of data to the $B M J$ and doubts that a major trial could have been undertaken by one man, who, as an immunologist, had also performed the psychometric testing used in the study.

Other factors fuelled concerns. One was the implausible number of digits remembered by the participants: 50 , when most people can remember only eight. The other was the fact that the mini-mental state examination scores suggested that the participants had substantial cognitive impairment, when they were reported in the study as "apparently healthy subjects." The $B M / \mathrm{s}$ statistical reviewer concluded that the data had "all the hallmarks of being entirely invented."

In June 2003 substantial doubts were aired in a letter in the Lancet about the 1992 trial (361:2247). Seth Roberts and Saul Sternberg, from the Universities of California at Berkeley and of Pennsylvania, respectively, together with Kenneth Carpenter from the University of California, pointed out: "The improvements [in the 1992 study] seemed large, and some of the standard errors were statistically impossible." The

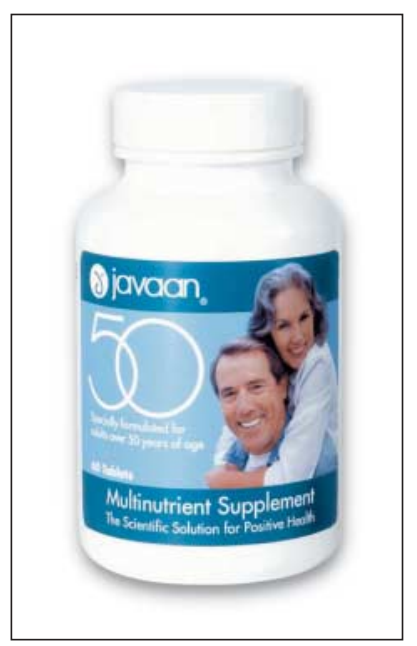

The patent for Javaan 50 multivitamin, marketed in the United States, is held by Professor Chandra

authors described other statistical problems and raised further doubts about the study. Professor Chandra dismissed these in a letter published in the same issue (361:2247-8).

In their recent letter in Nutrition Dr Roberts and Dr Sternberg comment: "The large number of problems with the 2001 paper ... make us doubt the data and their implications." They continue: "Similar problems ... about the 1992 Lancet study ... Chandra's failure to reply to letters about these issues, and his reply [to other authors], reduce its credibility even more."

Professor Chandra's response to this letter, published in the same issue of Nutrition (19:978-80), defends the biological plausibility of his work and attacks the validity of the two doctors' critique by questioning

\section{The improvements [in}

the 1992 study] seemed

large, and some of the

\section{standard errors were}

\section{statistically impossible}

their financial independence from drug companies.

In the accompanying editorial the editor in chief of Nutrition, Dr Michael Meguid, and its European editor, Alan Shenkin, regret that the paper's deficiencies escaped detection before publication. "It is with regret that we feel this response of the author, despite repeated requests from others and us, has failed to address the specific issues that have been raised," they write.

Professor Chandra holds the patent for the supplement, now marketed in North America as Javaan 50 by the Javaan Corporation. Amrita Gagnon, on behalf of the Javaan Corporation, told the $B M J$ that Javaan has licensed Dr Chandra's research for its formulation, with all royalties from this licence being donated directly to educational institutions. Ms Gagnon added that to date Dr Chandra has not received any proceeds from Javaan.

Chandra was a professor of immunology at the Memorial University of Newfoundland at St John's until his resignation in August 2002 after a period of unpaid leave. An officer of the Order of Canada, he received a distinguished service award from the Canadian Society for Nutritional Sciences in 1990.

In response to questions raised by Richard Smith, editor of the $B M J$, Memorial University replied in April 2001 that it was happy with Professor Chandra's research findings. But the $B M J$ queried whether these conclusions had been drawn from an examination of the study's raw data.
The university eventually wrote back in August 2002 to say that it took the allegations very seriously but that Professor Chandra had taken unpaid leave for the first four months of 2002 during which time he did not respond to any of its queries, including the university's request for the raw data. He then resigned at the beginning of August.

When the paper appeared in Nutrition the $B M J$ notified the editors of its concerns.

"The serious doubts over the paper submitted to us and the earlier study in the Lancet can be settled only by a full investigation by the university that includes an examination of the raw data. Professor Chandra is not cooperating with such an investigation," said Dr Smith.

In an email message from India, where he is now based, Professor Chandra told the $B M J$ : "I provided a very detailed point by point reply to each and every issue raised by the $B M J . "$ He said that several files of research studies went missing during an unauthorised search of his office in 2001.

But Dr Smith said, "We have not been satisfied by Professor Chandra's response to our questions. I think that it would be wise for the world to disregard these two studies unless Professor Chandra can prove their validity. There must also be doubts about other studies conducted by Professor Chandra, especially as he was the sole author on many of them. I have urged the university to investigate."

"When we went back to Chandra [a second time] he stopped cooperating with us," explained Dr Jack Strawbridge, director of labour relations at Memorial University, adding that the university felt that it no longer had any financial or other leverage over Professor Chandra as a former employee.

$\mathrm{He}$ said that the university had considered examining his previous research output. "But there are some 200 papers. That's a formidable undertaking and would require a forensic statistician," he said. "Furthermore, a very large proportion of his work is in a journal he edits."

"Perhaps the more urgent question that needs to be asked is: what should the international scientific community do about this?" he asked. 